\title{
In-Flight Entertainment Datalink Analysis and Simulation
}

\author{
Shahid Ayub \\ Center for Autonomous and Cyber \\ Physical Systems \\ SATM, Cranfield University \\ MK43 0AL, UK \\ shahid.ayub@cranfield.ac.uk \\ Saba Al-Rubaye \\ Center for Autonomous and Cyber \\ Physical Systems \\ SATM, Cranfield University \\ MK43 0AL, UK \\ S.Alrubaye@cranfield.ac.uk
}

\author{
Ivan Petrunin \\ Center for Autonomous and Cyber \\ Physical Systems \\ SATM, Cranfield University \\ MK43 0AL, UK \\ i.petrunin@cranfield.ac.uk \\ Gareth Stapylton \\ Thales Avionics, UK \\ Gareth.stapylton@uk.thalesgroup.com
}

\author{
Antonios Tsourdos \\ Center for Autonomous and Cyber \\ Physical Systems \\ SATM, Cranfield University \\ MK43 0AL, UK \\ a.tsourdos@cranfield.ac.uk \\ Gary Dent \\ Thales Avionics, UK \\ gary.dent@uk.thalesgroup.com
}

\begin{abstract}
In-Flight Entertainment (IFE) datalink is one of the airport connectivity areas, where efforts are being made by different stakeholders to improve and update the entertainment services offered to the passengers. An important objective of IFE datalink is to increase the flight operation efficiency by managing IFE data transfer within turnaround time which is about 45 minutes. With the rapid advancements and innovation in multimedia applications and services, the IFE data size in the future will turn into terabytes, therefore, this transfer requires a multi-Gbps datalink in order to be completed within expected turnaround time. This paper focuses on simulation of IFE datalink communication scenario at an airport surface using Wi-Fi (802.11ac) technology, provides rules and guidelines on suitability of wireless datalinks for IFE update at the airports, studies QoS requirements, and performs optimization. Several aspects of the IFE datalink selection and deployment have been considered, such as airport operational areas, airport layouts, radio frequency, and data congestion before conducting a capacity and coverage analysis.
\end{abstract}

Keywords-Airport connectivity, Datalink, In-flight entertainment, Wi-Fi, network performance, Riverbed modeler

\section{INTRODUCTION}

Currently, there is no standardized or globally agreed single data communication system deployed for IFE datalink systems. Various state of the art commercial systems are in operation at various airports. These systems do not have capability to support the rapidly growing traffic of future high-speed data applications. Therefore, it is essential to explore the potential wireless communication technologies for providing various data and voice services operated by stakeholders during a flight operation at the airport surface in the future.

Current mode of IFE data transfer (movies, games, etc.) is still manual with using physical hard drives to transfer required data. However, a limited use of existing Wi-Fi technology with representative throughputs of around $15 \mathrm{Mbps}$ is used at various airports terminals. At a large airport there is a possibility that IFE updates will be simultaneously requested by multiple aircraft; therefore, wireless networks for this large data transfer need to be carefully optimized to avoid congestion and quality of service (QoS) degradation [1], [2].

In [3], an analysis framework is developed to evaluate the performance of Aeronautical Mobile Airport Communications System (AeroMACS) networks for high data rate communications in the airport environment in support of Next Generation Air Transportation System (NextGen) operations. It evaluates the AeroMACS link performance and provides a study of interdependency between frequency planning and RF network planning for AeroMACS.

In the Nokia white paper [4], the goals and key requirements of the various wireless technologies available today for airport connectivity are examined. A purpose-built private wireless network architecture based on LTE/future $5 \mathrm{G}$ is presented to support data connectivity operations.

The current work investigates 802.11 ac wireless network for IFE updates scenario. It simulates the QoS mechanisms that can be exploited to avoid the network congestion and maximize the channel utilization. Also, an analysis of communication network infrastructure requirements for the IFE scenario at an airport have been deduced based on simulation work.

Based on above considerations, particular use cases for highcapacity, Wi-Fi deployment in Charles de Gaulle and Heathrow international airports were investigated in the simulated scenario. The simulation work considers the impact of large file transfers on network performance using the layouts of these airports. Riverbed modeler, formerly known as Optimized Network Evaluation Tool (OPNET) is used to carry out Wi-Fi datalink simulations. The optimization of network parameters (spatial streams, frame aggregation, Wireless Local Area Network Media Access Control (WLAN MAC) data buffer, QoS type) directly impacting the large data transfer have been discussed and performed.

Rest of the paper is organized as follows: In section II, IFE services and data requirements have been discussed. Section III summarizes the potential wireless communication technologies available for airport surface and provides the wireless bearer ranking criteria of these technologies (AeroMACS, LTE-A, Optical, Wi-Fi, mm wave) for IFE datalink. In Section IV, WiFi 802.11ac simulations are carried out to optimize the 
communication link for IFE updates using airport layouts. Finally, conclusions are drawn in Section V.

\section{IN FLIGHT ENTERTAINMENT SCENARIO APPLICATIONS \& DATALINK REQUIREMENTS}

IFE datalink services include transfer of media contents to aircraft, regular updates, secure data transfer, surveillance data application etc. Table 1 shows the different types of data applications delivered through IFE services.

\section{A. Applications}

Airlines are important stakeholders in IFE services. Other stakeholders include Original Equipment Manufacturer (OEM), service providers, spectrum regulators, airport authority, etc. Most of the IFE services are triggered as soon as aircraft arrives and parks at the gate zone. Since the average turnaround time for an aircraft is about $45-50$ minutes, and, to reduce the turnaround delays, IFE services updates need to be transferred to the aircraft within this time period. Therefore, this transfer requires a multi-Gbps data links. Current mode of IFE data transfer is manual, using physical hard drive or a limited use of Wi-Fi technology [5]. Table 2 provides a projection of IFE traffic volume transferred to an aircraft during a flight operation.

Table 1: In-Flight Entertainment Services

\begin{tabular}{|c|c|c|}
\hline Entertain Passengers & Inform Passengers & Support Cabin Crew \\
\hline $\begin{array}{c}\text { Airread/ Web-based } \\
\text { Apps }\end{array}$ & Concierge services & $\begin{array}{l}\text { Crew- to- Ground } \\
\text { Messaging }\end{array}$ \\
\hline $\begin{array}{l}\text { Audio/Video on } \\
\text { Demand }\end{array}$ & $\begin{array}{c}\text { Meal and Beverage } \\
\text { Menus }\end{array}$ & $\begin{array}{c}\text { Crew- to- Passenger } \\
\text { Messaging }\end{array}$ \\
\hline File viewer & Pay per Access & $\begin{array}{l}\text { Custom Script \& } \\
\text { Automation }\end{array}$ \\
\hline Games & Shopping & Parental Control \\
\hline $\begin{array}{c}\text { Personal Electronic } \\
\text { Device (PED) } \\
\text { Integration } \\
\end{array}$ & $\begin{array}{c}\text { Targeted } \\
\text { Advertisements }\end{array}$ & Wireless Crew Access \\
\hline Personalization & - & - \\
\hline
\end{tabular}

Table 2: IFE data load

\begin{tabular}{|c|c|c|c|c|c|}
\hline $\begin{array}{c}\text { Type of } \\
\text { Data }\end{array}$ & $\begin{array}{c}\text { Volume } \\
\text { /flight }\end{array}$ & Direction & Schedule & $\begin{array}{c}\text { Time to } \\
\text { update } \\
\text { @ } \\
15 \mathrm{Mbps}\end{array}$ & $\begin{array}{c}\text { Link } \\
\text { speed to } \\
\text { complete } \\
\text { in 45 min }\end{array}$ \\
\hline $\begin{array}{c}\text { IFE } \\
\text { Daily } \\
\text { Update }\end{array}$ & 20 GByte & $\begin{array}{c}\text { Ground- } \\
\text { to-aircraft }\end{array}$ & Daily & $3 \mathrm{hrs}$ & $61 \mathrm{Mbps}$ \\
\hline $\begin{array}{c}\text { IFE } \\
\text { Weekly } \\
\text { Update }\end{array}$ & $100 \mathrm{GByte}$ & $\begin{array}{c}\text { Ground- } \\
\text { to-aircraft }\end{array}$ & Weekly & $15 \mathrm{hrs}$ & $303 \mathrm{Mbps}$ \\
\hline $\begin{array}{c}\text { IFE } \\
\text { Monthly } \\
\text { Update }\end{array}$ & 500 GByte & $\begin{array}{c}\text { Ground- } \\
\text { to-aircraft }\end{array}$ & Monthly & $75 \mathrm{hrs}$ & $1517 \mathrm{Mbps}$ \\
\hline
\end{tabular}

\section{B. Scenario requirements}

It can be seen from the Table 2 that with standard Wi-Fi technology transmitting at $15 \mathrm{Mbps}$, it requires 3 hours to download IFE daily updates and similarly 15 and 75 hours for weekly and monthly updates respectively. The average time of stay of an aircraft at gate is about 45-50 minutes and IFE data needs to be transmitted within this time period. This shows that there is a need to explore the wireless technologies fulfilling the link speed requirements. In the next section, the criteria of wireless bearer selection have been discussed in detail.

\section{WIRELESS BEARER'S SELECTION ANALYSIS}

In the previous section, the formulation and requirement analysis of IFE datalink scenario has been carried out. This section provides a criterion for ranking of wireless technologies for IFE datalink communications. Wireless technologies, like Wi-Fi, AeroMACS, LTE/5G, Visible Light Communication (VLC)/LASER, and mmwaves could be proposed for IFE services updates. To rank these wireless bearers for IFE datalink scenario, the current capabilities and characteristics of these technologies and scenario requirements have been considered. In addition to those, the hardware cost, running cost, health \& safety and availability of equipment tailored for aircraft industry are also taken into consideration as shown in Table 3 [6]. Different wireless technologies for airport surface connectivity are proposed which include:

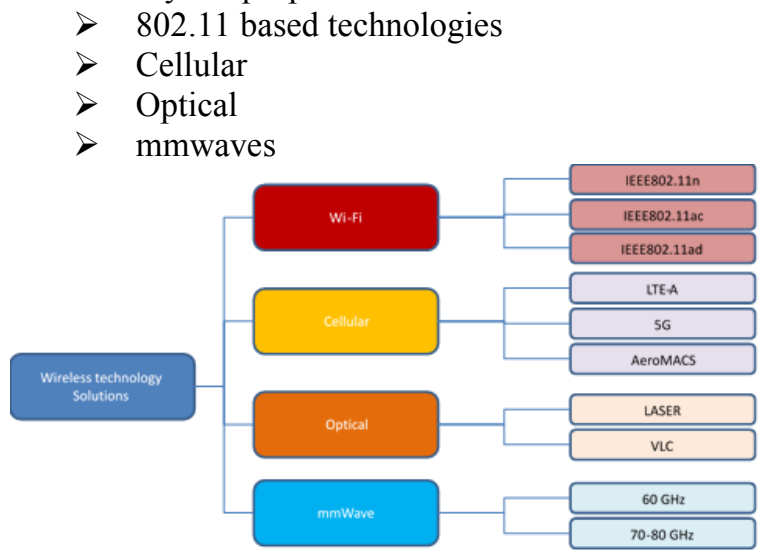

Figure 1: Potential wireless bearers for airport connectivity

The important characteristics of each technology have been summarized in Table 3.

Table 3: Wireless technologies characteristics

\begin{tabular}{|l|c|c|c|l|c|}
\hline $\begin{array}{c}\text { Characterist } \\
\text { ics/bearers }\end{array}$ & AeroMACS & 4G/LTE & $\begin{array}{c}\text { Wi-Fi } \\
(802.1 \\
1 \mathrm{n}, \mathrm{ac})\end{array}$ & $\begin{array}{l}\text { VLC/ } \\
\text { LASER }\end{array}$ & mm-waves \\
\hline & & $800 /$ & & & \\
& & $900 /$ & & & \\
Frequency & $5.091-5.150$ & $1800 /$ & $2.4,5$ & $400 \mathrm{THz}-$ & $60,70,80$ \\
& $\mathrm{GHz}$ & $2100 /$ & $\mathrm{GHz}$ & $750 \mathrm{THz}$ & $\mathrm{GHz}$ \\
& & 2600 & & & \\
\hline & & $\mathrm{MHz}$ & & & \\
\hline \multirow{2}{*}{ Spectrum } & Licensed & $\begin{array}{c}\text { License } \\
\mathrm{d}\end{array}$ & $\begin{array}{c}\text { Unlice } \\
\text { nsed }\end{array}$ & $\begin{array}{c}\text { Unlicense } \\
\mathrm{d}\end{array}$ & $\begin{array}{c}\text { Licensed } \\
\& \\
\text { Unlicensed }\end{array}$ \\
\hline
\end{tabular}




\begin{tabular}{|c|c|c|c|c|c|}
\hline $\begin{array}{l}\text { Characterist } \\
\text { ics/bearers }\end{array}$ & AeroMACS & 4G/LTE & $\begin{array}{l}\text { Wi-Fi } \\
(802.1 \\
1 \mathrm{n}, \mathrm{ac})\end{array}$ & $\begin{array}{l}\text { VLC/ } \\
\text { LASER }\end{array}$ & mm-waves \\
\hline Data Rate & $\begin{array}{l}\text { Up to } 10 \\
\text { Mbps }\end{array}$ & $\begin{array}{l}\text { Up to } \\
100 \\
\text { Mbps }\end{array}$ & $\begin{array}{l}\text { Up to } \\
0.6 / 1 \\
\text { Gbps }\end{array}$ & $\begin{array}{l}\text { Multi } \\
\text { Gbps }\end{array}$ & $\begin{array}{l}\text { Up to } 10 \\
\text { Gbps }\end{array}$ \\
\hline Range & $3 \mathrm{~km}$ & $30 \mathrm{~km}$ & $\begin{array}{l}\text { Up to } \\
300 \mathrm{~m}\end{array}$ & $\begin{array}{c}\text { Varies } \\
\text { (LED } \\
\text { power) } \\
\text { Indoor } 5 \\
\text { m }\end{array}$ & $\begin{array}{l}\text { Up to } 3 \mathrm{~km} \\
\text { for }(70-80 \\
\mathrm{GHz})\end{array}$ \\
\hline $\begin{array}{l}\text { Channel } \\
\text { Bandwidth }\end{array}$ & $20 \mathrm{MHz}$ & $\begin{array}{l}1.4-20 \\
\mathrm{MHz}\end{array}$ & $\begin{array}{c}20, \\
40, \\
80, \\
160 \\
\mathrm{MHz} \\
\end{array}$ & $\begin{array}{c}\text { Large } \\
\text { bandwidt } \\
\text { h } \\
\text { available }\end{array}$ & $\mathrm{Up}$ to $\mathrm{GHz}$ \\
\hline Latency & $<10 \mathrm{~ms}$ & $<5 \mathrm{~ms}$ & $\begin{array}{c}<100 \\
\mathrm{~ms}\end{array}$ & unknown & $<5 \mathrm{~ms}$ \\
\hline Mobility & $57.5 \mathrm{mph}$ & $\begin{array}{l}280 \\
\mathrm{mph}\end{array}$ & $\begin{array}{l}\text { walkin } \\
\mathrm{g}\end{array}$ & & walking \\
\hline
\end{tabular}

Table 4: Criteria for wireless bearers ranking

\begin{tabular}{|l|l|l|l|}
\hline $\begin{array}{l}\text { Characteristics/ } \\
\text { weights }\end{array}$ & 1 & 2 & 3 \\
\hline Data rate & $<1 \mathrm{Mbps}$ & $1 \mathrm{Mbps}<\mathrm{DR}<100 \mathrm{Mbps}$ & $\begin{array}{l}>100 \\
\mathrm{Mbps}\end{array}$ \\
\hline Range & $<25 \mathrm{~m}$ & $50 \mathrm{~m}<$ range $<3$ miles & $\begin{array}{l}>3 \\
\text { miles }\end{array}$ \\
\hline Mobility & $<5 \mathrm{mph}$ & $5 \mathrm{mph}<$ speed $<60 \mathrm{mph}$ & $\begin{array}{l}>60 \\
\mathrm{mph}\end{array}$ \\
\hline Security/Reliability & low & moderate & high \\
\hline Hardware availability & $<$ TRL5 & $\begin{array}{l}\text { TRL5 }<\text { Availability } \\
<\text { TRL9 }\end{array}$ & TRL9 \\
\hline Hardware cost & high & moderate & low \\
\hline Running cost & high & moderate & low \\
\hline Health \& safety & Low & Moderate & high \\
\hline
\end{tabular}

The criteria mentioned in Table 4 have been used to rank the wireless bearers IFE datalink. The selected wireless bearers have been assigned weights based on these characteristics in Table 5. For example, the VLC has high data rate so it is assigned a weight equal to 3 . The range of VLC is very short i.e., few meters only, so range is assigned a weight of 1 . Mobility is not supported in VLC at the moment, so its weight is 1 .

Table 5: Ranking of wireless bearers with respect to criteria

\begin{tabular}{|l|l|l|l|l|l|l|l|}
\hline $\begin{array}{l}\text { Characteristics/Be } \\
\text { arers }\end{array}$ & $\begin{array}{l}\text { Aero } \\
\text { MAC } \\
\mathrm{S}\end{array}$ & $\begin{array}{l}\text { LTE/ } \\
5 \mathrm{G}\end{array}$ & $\begin{array}{l}\mathrm{W} \\
\mathrm{i}- \\
\mathrm{Fi}\end{array}$ & $\begin{array}{l}\mathrm{VL} \\
\mathrm{C}\end{array}$ & $\begin{array}{l}\mathrm{mm} \\
\text { wa } \\
\text { ve }\end{array}$ & $\begin{array}{l}\text { VD } \\
\text { L- } \\
\text { M2 }\end{array}$ & $\begin{array}{l}\text { Las } \\
\text { er }\end{array}$ \\
\hline Data Rate & 2 & 2 & 3 & 3 & 3 & 1 & 3 \\
\hline Range & 2 & 2 & 2 & 1 & 2 & 3 & 2 \\
\hline Mobility & 2 & 3 & 1 & 1 & 1 & 3 & 1 \\
\hline Security/Reliability & 3 & 3 & 1 & 1 & 2 & 2 & 3 \\
\hline $\begin{array}{l}\text { Hardware } \\
\text { Availability }\end{array}$ & 3 & 3 & 3 & 1 & 2 & 3 & 3 \\
\hline Hardware Cost & 1 & 1 & 3 & 1 & 1 & 1 & 1 \\
\hline Running Cost & 3 & 1 & 3 & 3 & 3 & 1 & 3 \\
\hline Health \& Safety & 2 & 2 & 2 & 3 & 2 & 2 & 1 \\
\hline
\end{tabular}

Currently, VLC products are not commercially available and current prototypes are very costly and do not implement security policies so each of security, hardware availability and cost criteria are assigned a weight of 1 . The running cost of VLC is low and is assigned a weight equal to 3 .

Finally, visible light is not hazardous to human health and safety, so is assigned a weight of 3 . In Table 6, each of the criteria have been assigned a weight based on IFE datalink scenario requirements. For example, for the IFE scenario, we require a high data rate, so data rate is given a weight of 3 . We are mostly interested to provide a wireless coverage to aircraft at gate terminal which are usually parked within $150 \mathrm{~m}$ distance from terminal building so a weight equal to 2 is assigned to range. Also, for IFE scenario, data transmission will take place while aircraft are parked or approaching to gate at very low speed so there is very low mobility and it is assigned a weight of 1 .

Table 6: Ranking of bearers' characteristics w.r.t. IFE datalink scenario

\begin{tabular}{|c|c|c|c|c|c|c|c|c|c|}
\hline $\begin{array}{c}\text { Scenar } \\
\text { io / } \\
\text { Chara } \\
\text { cteristi } \\
\text { cs }\end{array}$ & $\begin{array}{c}\text { Data } \\
\text { rates }\end{array}$ & $\begin{array}{c}\text { Ran } \\
\text { ge }\end{array}$ & $\begin{array}{c}\text { Mob } \\
\text { ility }\end{array}$ & $\begin{array}{c}\text { Securit } \\
\text { y/Relia } \\
\text { bility }\end{array}$ & $\begin{array}{c}\text { Hardware } \\
\text { Availabilit } \\
\text { y }\end{array}$ & $\begin{array}{c}\text { Hardw } \\
\text { are } \\
\text { cost }\end{array}$ & $\begin{array}{c}\text { Run } \\
\text { ning } \\
\text { cost }\end{array}$ & $\begin{array}{c}\text { Hea } \\
\text { th } \\
\text { Safe } \\
\text { ty }\end{array}$ \\
\hline $\begin{array}{c}\text { Scenar } \\
\text { io A - } \\
\text { IFE }\end{array}$ & 3 & 2 & 1 & 1 & & 1 & 3 & 3 & 3 \\
\hline
\end{tabular}

Table 7: Ranking of wireless bearers for IFE datalink scenario

\begin{tabular}{|c|c|c|c|c|c|c|c|}
\hline $\begin{array}{c}\text { Scenario / } \\
\text { Characteristi } \\
\text { cs }\end{array}$ & $\begin{array}{c}\text { AeroMA } \\
\text { CS }\end{array}$ & LTE/5G & $\begin{array}{c}\text { Wi } \\
\text {-Fi }\end{array}$ & $\begin{array}{c}\text { VL } \\
\text { C }\end{array}$ & $\begin{array}{c}\text { mm- } \\
\text { wave }\end{array}$ & $\begin{array}{c}\text { VDL- } \\
\text { M2 }\end{array}$ & $\begin{array}{c}\text { Lase } \\
\text { r }\end{array}$ \\
\hline $\begin{array}{c}\text { Scenario A - } \\
\text { IFE }\end{array}$ & 36 & 31 & 42 & 35 & 36 & 29 & 35 \\
\hline
\end{tabular}

For IFE data transfer, high secure link is not required as data to be transferred is not very sensitive so it is assigned a 1 weight. We are looking for low cost hardware, low running cost and safe solution for IFE scenario so these are assigned a weight equal to 3.

Finally, in Table 7, a weighted sum is calculated to assign the wireless bearers to IFE datalink scenario. Based on the above criteria, $\mathrm{Wi}-\mathrm{Fi}$ is turned to be the most suitable wireless bearers for the IFE scenario. The upcoming $5 \mathrm{G}$ technology which is promising high data rates in Gbps is one of the strong candidates for future airport connectivity. Other potential candidates for the IFE scenario include millimetre wave technology and visible light communication where a data rate of $10 \mathrm{Gbps}$ is expected. These two potential technologies are still under research phase and their products are not available off-the-shelves at present. In the future, with the advancement in technologies, the criteria weights for the wireless bearers may change which can alter the choice the wireless bearers for the IFE scenario.

AeroMACS equipment is currently manufactured by Siemens and have been deployed at the few airports as test bed. It 
provides secure data communication, and the maximum data speed available is $10 \mathrm{Mbps}$ which is suitable for low data rate applications. The running cost of LTE/4G will become high in case of the large data file transfer however it provides sufficient reliability, security and range. LASER beam requires high line of sight synchronization with the receiver. Since the laser beam is dangerous for health and safety purpose it is generally used for site to site communication installed at high buildings. VLC and mmwaves technologies are considered to be most promising technologies for future high data rate applications scenarios like IFE. However, these technologies still under technology readiness level (TRL) 4 or 5 . Wi-Fi is the most economical and readily deployable available solution that can provide a sufficient coverage at terminal along with high data rates up to Gbps with latest Wi-Fi 802.11ac and 802.11ax standards. Table 3 shows the criteria of these wireless bearers' assignment for three airport connectivity scenarios selected in this study.

\section{IFE DATALINK SIMULATIONS}

Table 8 describes the set of simulations scenarios which have been carried out in this section using Wi-Fi technology while taking into consider the requirements of IFE datalink scenario described in section I.

Table 8: IFE datalink simulation scenarios

\begin{tabular}{|c|c|c|c|}
\hline $\begin{array}{c}\text { Scenari } \\
0\end{array}$ & \multicolumn{2}{|c|}{ Scenario Description } & Attributes \\
\hline SC-1 & \multicolumn{2}{|c|}{$\begin{array}{l}\text { Communication range } \\
\text { simulation }\end{array}$} & $\begin{array}{l}\text { IEEE802.11ac, Transmission } \\
\text { power Vs Range } \\
50 \mathrm{~mW}, 100 \mathrm{~mW}, 150 \mathrm{~mW}, 200 \mathrm{~mW} \text {, } \\
250 \mathrm{~mW}, 500 \mathrm{~mW}, 1 \mathrm{~W}, 5 \mathrm{~W}, 10 \mathrm{~W}\end{array}$ \\
\hline $\mathrm{SC}-2$ & \multicolumn{2}{|c|}{$\begin{array}{l}\text { Optimizing network for } \\
\text { IFE scenario }\end{array}$} & $\begin{array}{l}\text { IEEE802.11ac, VHT (4 Spatial } \\
\text { Streams), Guard interval (400ns), } \\
\text { Frame aggregation (A-MSDU, A- } \\
\text { MPDU), WLAN MAC data } \\
\text { buffer size, QoS }\end{array}$ \\
\hline SC-3 & \multicolumn{2}{|c|}{ No. of aircraft simulation } & Aircraft $1,2,3,4,5,10$ \\
\hline SC-4 & \multicolumn{2}{|c|}{ Data file sizes simulation } & $\begin{array}{l}200 \mathrm{MB}, 500 \mathrm{MB}, 1 \mathrm{~GB}, 2 \mathrm{~GB}, \\
5 \mathrm{~GB}, 10 \mathrm{~GB}, 20 \mathrm{~GB}\end{array}$ \\
\hline \multirow{2}{*}{ SC-5 } & \multirow{2}{*}{$\begin{array}{l}\text { Topolo } \\
\text { gy } \\
\text { optimiz } \\
\text { ation } \\
\text { simulat } \\
\text { ion }\end{array}$} & $\begin{array}{l}\text { SC-5.1 } \\
\text { Heathrow } \\
\text { terminal 5B }\end{array}$ & \multirow{2}{*}{$\begin{array}{l}\text { Network topology with different } \\
\text { no of base stations }\end{array}$} \\
\hline & & $\begin{array}{l}\text { SC-5.2 } \\
\text { Charles de } \\
\text { Gaulle } \\
\text { terminal } 1\end{array}$ & \\
\hline
\end{tabular}

Riverbed Modeler, formerly known as OPNET is used to carry out Wi-Fi datalink simulations. Riverbed Modeler (formerly called OPNET) is a popular network simulation software package [7]. It provides a flexible and accurate simulation platform for evaluating the performance of various networking protocols. The process models of the network nodes are implemented in the programming language called Proto-C, and are constructed by using finite state machine (FSM)-based transition diagrams. The features of Riverbed software allow the test of standardized protocols (such as TCP/IP), as well as the development of new communication protocols and networking paradigms [8].

Our focus in Wi-Fi simulation work will be mostly on $802.11 \mathrm{n}$ and $802.11 \mathrm{ac}$ standards. Since, the theoretical data rates for $802.11 \mathrm{n}$ is about $600 \mathrm{Mbps}$ and for that of $802.11 \mathrm{ac}$ is about $3.12 \mathrm{Gbps}$, therefore, these two protocols are more promising the link speed requirements of current IFE data traffic transfer. However, the practical range of 802.11ac is smaller in comparison to $802.11 \mathrm{n}$.

The maximum communication distance between two WLAN nodes is a function of three parameters: the transmission power of the sending node, the path-loss propagation model, and the reception power threshold (receiver sensitivity) of the receiving node [9]. The IEEE 802.11 standard limits the distance between WLAN nodes to $300 \mathrm{~m}$. Therefore, WLAN networks that extend beyond $300 \mathrm{~m}$ might incur a performance degradation in the WLAN MAC algorithm. Based on the configured values of transmission power parameter, we can model WLAN networks to increase the communication range more than $300 \mathrm{~m}$.

The receiver sensitivity concept that is implemented through the reception power threshold attribute ensures that the packets with a reception power lower than the threshold cannot make the receiver lock onto their signal and will be treated as noise packets.

\section{A. Communication range simulation}

Objective: The objective of SC-1 is to simulate the maximum range of Wi-Fi 802.11 ac standard in terms of link connectivity. Network Topology: Figure 2 shows the network topology and configuration used for simulation carried out to determine the range of $802.11 \mathrm{ac}$ standard. The transmission power is set to $250 \mathrm{~mW}$. A constant packet size of 2304 bytes are sent from source to destination. Destination node is moved away from source with a constant distance interval of $10 \mathrm{~m}$. The maximum distance up to which communication link can be established is observed.

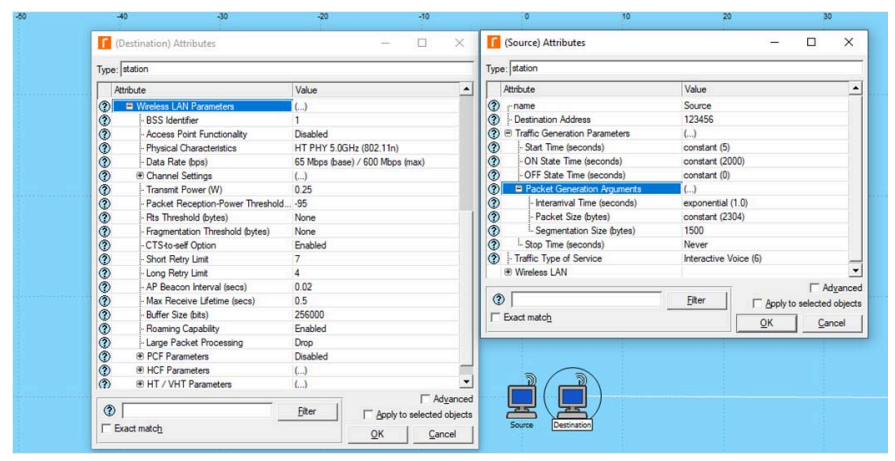

Figure 2: Network topology and configuration for communication range simulation

Result Analysis: In the current simulation, the communication 
range of the standard is meant as the point up to which Wi-Fi link connectivity can be established. Since the aircraft present at the terminal gate is within $150 \mathrm{~m}$ coverage area so $802.11 \mathrm{ac}$ is providing sufficient range for transmission as shown in Figure 3 . In addition, this range can be increased by increasing transmission power level. Riverbed is currently not supporting rate adaptation mechanism, so throughput remains constant until a distance where packet drop starts occurring due to decrease in signal strength.

Figure 3 shows the simulation where an omni-directional antenna with $7 \mathrm{~dB}$ gain is used for both TX and RX. The TX power level is set to $250 \mathrm{~mW}(24 \mathrm{dBm})$. This simulation is carried out for $10 \mathrm{~m}$ to $150 \mathrm{~m}$, it has been observed that RSSI level is decreased from $-38.8 \mathrm{dBm}$ to $-62.33 \mathrm{dBm}$ as the distance is varied from $10 \mathrm{~m}$ to $150 \mathrm{~m}$.

The activities carried out under this simulation provide an understanding of variation of received power and communication range with given TX power level of the Wi-Fi transmitter and also provide an insight into transmission power requirement if we need to provide wider coverage to more aircraft at the terminal parked at apron or remote areas.

Table 9: Parameters configuration for RSSI vs distance

\begin{tabular}{|c|c|}
\hline Wi-Fi standard & $802.11 \mathrm{ac}, 78 \mathrm{Mbps}$ base rate \\
\hline Spatial streams & $1 \mathrm{X} 1$ \\
\hline Packet size & $2304 \mathrm{~B}$ \\
\hline Number of users & 1 \\
\hline TX Power level & $250 \mathrm{~mW}(24 \mathrm{dBm})$ \\
\hline Distances & $10 \mathrm{~m}$ to $150 \mathrm{~m}$ \\
\hline
\end{tabular}

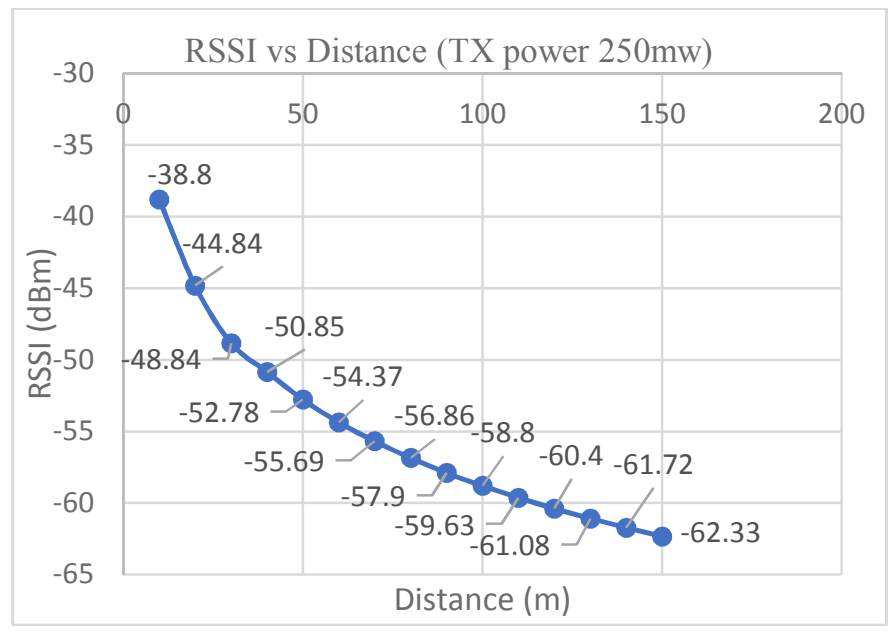

Figure 3: RSSI vs distance (TX power $250 \mathrm{~mW}$ - omnidirectional antenna $7 \mathrm{~dB}$ )

\section{B. Network performanc Optimization}

Objective: In this scenario, 802.11 ac standard is optimized for IFE scenario to transfer the data from IFE server to aircraft. As discussed in Table 2, IFE data need to be transferred to aircraft with in a turn-around time of 45-50 minutes. In this simulation, different optimizing parameters have been considered and impact of these parameters have been analyzed on network statistics such as throughput and download response time, etc., [9]. These parameters have been summarized in the Table 10.

Network Topology: Figure 4 shows the network topology of this scenario, which consist of an FTP server, Ethernet switch, wireless router and a wireless aircraft node. An FTP server, Ethernet switch and wireless access point are connected with each other using a gigabit Ethernet link. In this simulation, FTP server is configured to transfer a $1 \mathrm{~GB}$ file (IFE update) when requested by an aircraft user.

At first simulation is run using standard service that falls in access category 0 . Then the type of service is changed to expedited forwarding (EF- Interactive multimedia). This service has the characteristics of low delay, low loss and low jitter. EF traffic is often given strict priority queuing above all other traffic classes and provides necessary QoS.

A profile with above FTP application is set in the network and applied to both aircraft client and IFE server. IEEE802.11ac is configured to deploy in this model with $78 \mathrm{Mbps}$ basic rate, 1 spatial data stream and Guard Interval is set to $800 \mathrm{~ns}$. The transmit power is set to $250 \mathrm{~mW}$ and buffer size is set to $2 \mathrm{Mbits}$. First simulation is carried out to analyze the impact of WLAN MAC data buffer size on the network performance. The value of this parameter specifies the maximum size of the higher layer data buffer in bits. Once the buffer limit is reached, the data packets arrived from higher layer will be discarded until some packets are removed from the buffer so that the buffer has some free space to store these new packets. If the buffer size is too small and application is processing data very fast, packet drop rate can increase. Usually, a rule of thumb for initial estimate of data buffer size is equal to buffer size $=\mathrm{T} \mathrm{C}$, where $\mathrm{T}$ is round trip time and $\mathrm{C}$ is the capacity of link.

Table 10: Network optimization parameters for IFE scenario

\begin{tabular}{|c|c|c|c|}
\hline Parameters & Values & Impact & $\begin{array}{c}\text { Typical/Default } \\
\text { parameters }\end{array}$ \\
\hline Buffer size & 2Kbits & $\begin{array}{c}\text { Reduce } \\
\text { packet drop, } \\
\text { increase } \\
\text { throughput }\end{array}$ & 256Kbits \\
\hline $\begin{array}{c}\text { QoS (AIFS, } \\
\text { contention } \\
\text { window size } \\
\text { etc.) }\end{array}$ & $\begin{array}{c}\text { EF (Interactive } \\
\text { multimedia) }\end{array}$ & $\begin{array}{c}\text { Increase } \\
\text { channel } \\
\text { utilization, } \\
\text { Increase } \\
\text { throughput }\end{array}$ & Standard \\
\hline $\begin{array}{c}\text { No of spatial } \\
\text { streams }\end{array}$ & $1-4$ & $\begin{array}{c}\text { Increase } \\
\text { throughput }\end{array}$ & 1 \\
\hline $\begin{array}{c}\text { Guard } \\
\text { interval }\end{array}$ & $800 \mathrm{~ns}$ - 400ns & $\begin{array}{c}\text { Increase } \\
\text { throughput }\end{array}$ & $800 \mathrm{~ns}$ \\
\hline $\begin{array}{c}\text { Frame } \\
\text { Aggregation }\end{array}$ & $\begin{array}{c}\text { A-MPDU, A- } \\
\text { mode enabled }\end{array}$ & $\begin{array}{c}\text { Increase } \\
\text { throughput }\end{array}$ & Disabled \\
\hline $\begin{array}{c}\text { Application } \\
\text { processing } \\
\text { speed }\end{array}$ & $40 \mathrm{MB} / \mathrm{s}$ & $\begin{array}{c}\text { Reduce } \\
\text { processing } \\
\text { delays }\end{array}$ & $1 \mathrm{MB} / \mathrm{s}$ \\
\hline
\end{tabular}


The optimal buffer size depends on several network environment factors including types of switches and systems, acknowledgment timing, error rates and network topology, memory size, and data file size. When data file size is extremely large, we might want to set the buffer sizes to an optimized value to improve throughput, and reduce the occurrence of flow control issues.

QoS deals with providing end-end guarantee to the users, these guarantees may include parameters like bandwidth and latency guarantees, packet loss, and congestion control [10]. Following are the main QoS requirements that can be considered in the aircraft communication system design:

Priority classification: A QoS policy should specify what priority level to be given for each traffic flow. The QoS manager shall be able to tag/mark the data coming from the four different domains according to prior information available about the IP addresses and ports of the communicating entities. Traffic Queuing \& Scheduling: The system shall place packets in different queues according to their priority levels. Afterwards, schedulers will pick packet to be served according to their priorities.

Enhanced Distributed Channel Access (EDCA): EDCA is designed to provide prioritized QoS [4] by enhancing the contention based DCF. It provides eight different user priorities. Before entering the MAC layer, each data packet received from higher layer is assigned a specific user priority value. The EDCF mechanism defines four different queues called access categories (ACs) that provide support for the delivery of traffic with user priorities at the QoS stations [5].

By using multiple antennas for input and output (MIMO), the spatial diversity can be exploited that uses multiple parallel streams for data transmission. Theoretically, the data rate increase is a factor of number of streams of the base data rate and hence the throughput [11].

In this simulation, an important MAC enhancements mechanism of frame aggregation is implemented, which maximizes throughput and efficiency of the wireless system. There are three methods available to perform frame aggregation: Aggregate MAC service data unit (A-MSDU), Aggregate MAC protocol data unit (A-MPDU) and hybrid AMSDU/A-MPDU aggregation.

The main difference between an MSDU and an MPDU is that the former corresponds to the information that is imported to or exported from the upper part of the MAC sublayer from or to the higher layers, respectively, whereas the later relates to the information that is exchanged from or to the PHY by the lower part of the MAC. Aggregate exchange sequences are made possible with a protocol that acknowledges multiple MPDUs with a single block ACK in response to a block acknowledgment request (BAR). The principle of the A-MSDU is to allow multiple MSDUs to be sent to the same receiver concatenated in a single MPDU. This improves the efficiency of the MAC layer, specifically when there are many small MSDUs, such as TCP acknowledgments. For an A-MSDU to be formed, a layer at the top of the MAC receives and buffers multiple packets (MSDUs). The A-MSDU is completed either when the size of the waiting packets reaches the maximal AMSDU threshold. Its maximum length can be either 3839, 7935 or 11454bytes.

Results Analysis: In this section, different parameter configurations have been considered which can be used to enhance the user throughput in the wireless network. It has been observed that frame aggregation is an important mechanism which reduces the overhead data in the network and increases the network throughput and channel utilization significantly compared to other parameters.

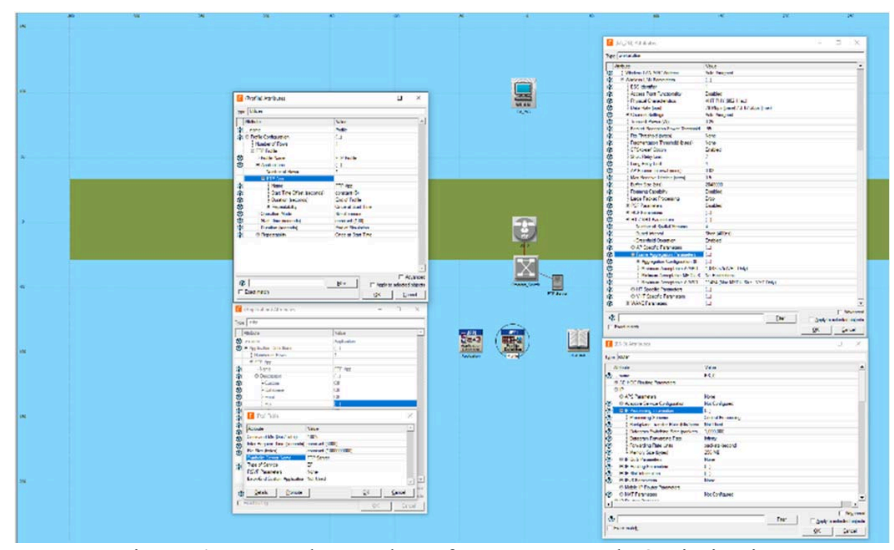

Figure 4: Network Topology for IFE Network Optimization

By changing the type of service, we can set the different values for parameters which define the priority level and channel access category. These parameters include contention window size, inter frame spacing and slot time etc. In this simulation FTP data has been transferred by varying the different channel access categories to see an effect on user throughput. WLAN MAC buffer size is another important parameter in large file size transfer, and it needs to be optimized according to data size so that packet drop rate due to transmission queues overflow can be minimized [7]. In this simulation, it has been observed that a MAC buffer size of $4 \mathrm{MB}$ is optimal to transfer a data size of GB. Other parameters for throughput enhancement include number of parallel spatial streams and guard interval and server processing speed. By increasing number of spatial streams, user throughput is increased and also it increases the reliability of data reception and mitigate the multipath effect. These optimized parameters configuration is used further for IFE simulation in this work.

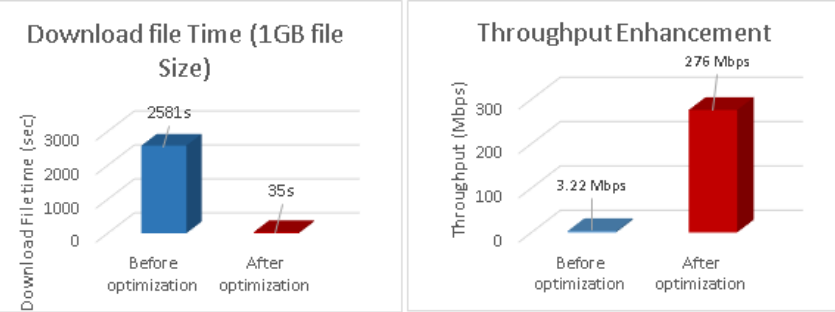

Figure 5: Network parameters optimization impact on user throughput and download file time 


\section{No of Users Effects on Network Performance}

Objectives: This simulation is performed to analyze the effect of increasing number of aircraft (users) on network performance. As a greater number of aircraft approach to the gate, they will be connected with base station to start IFE data transfer, as a result, the network load increases and can create congestion in the network. This simulation will also provide an idea of limit in number of users that should be associated with base station for large file transfer applications.

Network Topology: The configuration of this simulation is based on the optimized parameters obtained in SC-2. The user throughput is expected to decrease in multi user scenario due to the need to coordinate how different stations should share the resources as well as how to resolve contention experienced by each station when accessing the medium. In this simulation, the number of aircraft are varied $(1,2,5$, and 10) with the same application (1GB file size) and profile configurations in order to study the user throughput loss. A wireless router is used as an access point and wireless configuration is set to IEEE 802.11ac with physical data rate of 78Mbps. Number of users are varied $(1,2,5,10)$ and all the users are within the radius of $100 \mathrm{~m}$. Each user sends a request to FTP server to download a file of size $1 \mathrm{~GB}$ once a time during simulation period.

Figure 6 shows the change in user throughput as the number of aircraft are increased in the network. It has been observed that average throughput/user is decreased from $276 \mathrm{Mbps}$ to $87 \mathrm{Mbps}$ as the number of aircraft are increased from 1 to 10 .

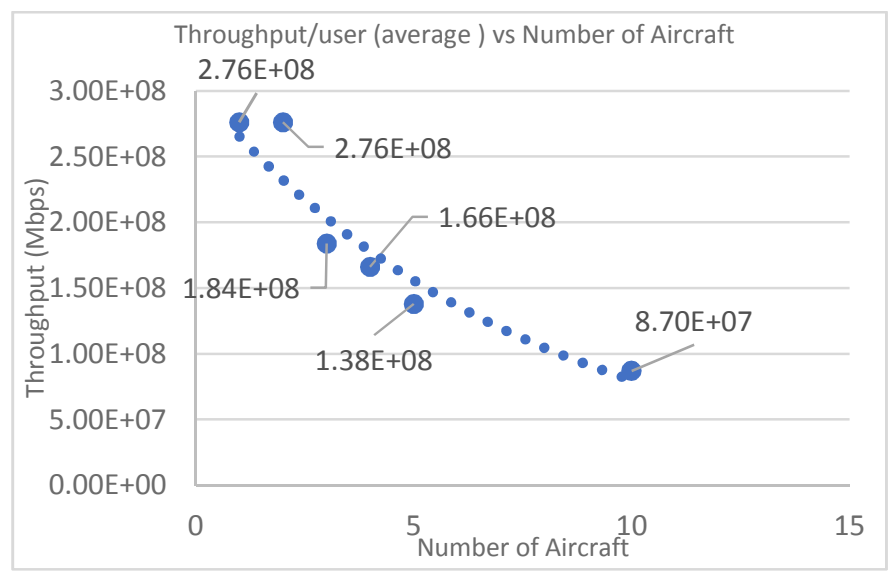

Figure 6: Effect on throughput by increasing number of users

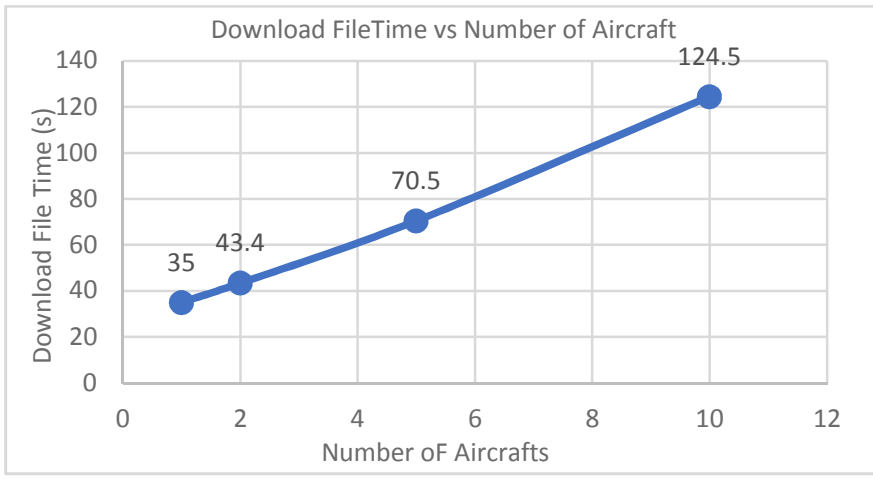

Figure 7: Download file time vs number of aircraft
With an increase of number of aircraft, there are more contender for same channel, and if channel is busy the users have to wait to get access to channel to transmit data that will increase the download file time. The download file time is increased from $35 \mathrm{~s}$ to $124.5 \mathrm{~s}$ as the number of users are increased from 1 to 10 (Figure 7). File Size Effect on Network Performance

\section{File Size Effect on Network Performance}

Objectives: This simulation is performed to analyze the effect of increasing data transfer size (file size) on network performance using TCP protocol. TCP protocol ensures that data transfer between two entities is received correctly and in order without any loss of data. As data file size is increased, there will be less overhead data to be transferred compared to small file sizes which results in an increment in channel utilization, and throughput should increase subject to wireless link capacity. The simulation is carried out for the following file size: $200 \mathrm{MB}, 500 \mathrm{MB}, 1 \mathrm{~GB}, 2 \mathrm{~GB}, 5 \mathrm{~GB}, 10 \mathrm{~GB}$, and $20 \mathrm{~GB}$.

Results Analysis: It has been observed that with an increase in file size throughput/user is also increased until it reaches to saturation point depending upon channel capacity. It can also be observed from user throughput formula which can be calculated as follows:

$$
\text { Throughput }=\frac{\text { No. of packets } X \text { packet size } X 8}{\text { Total duration of transfer }}
$$

The duration of transfer includes transmission delays, propagation delays and processing delays.

In this simulation with an increase of file size from $200 \mathrm{MB}$ to $20 \mathrm{~GB}$, the throughput is increased from $55.24 \mathrm{Mbps}$ to approximately $1 \mathrm{Gbps}$ as shown in Figure 8. Figure 9 shows the corresponding download file time for each file size.

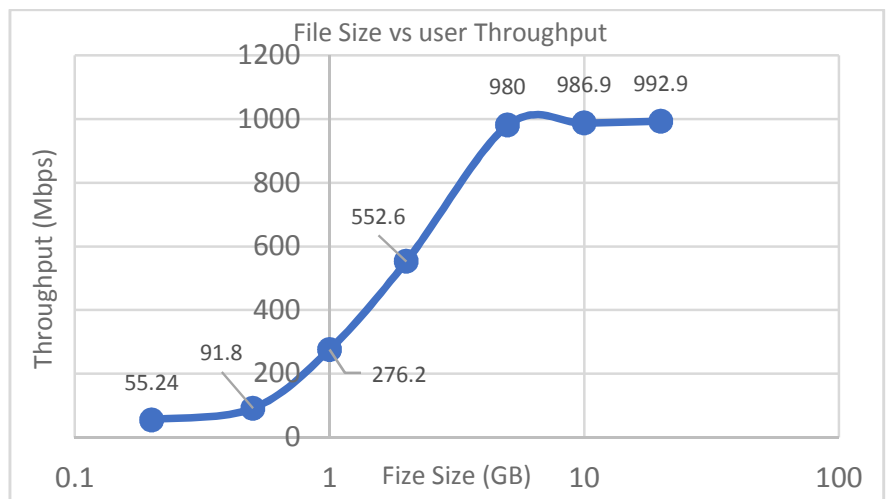

Figure 8; File size vs user throughput 


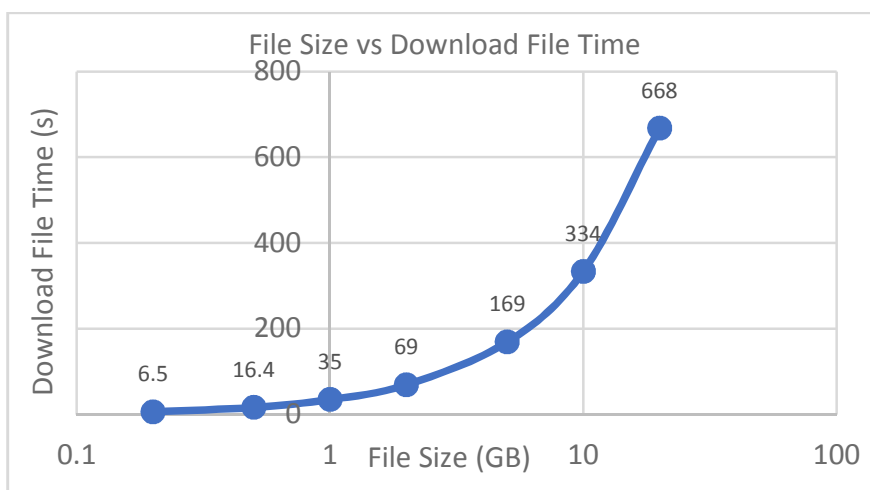

Figure 9: File size vs download file time

\section{E. SC-6 Network Topology Optimization for Airport Layouts}

\section{SC-6.1 Heathrow Airport Terminal 5B Simulation}

Objective: In this simulation, the actual layout of the Heathrow airport terminal 5 is used. These simulations also provide an insight into the cost of infrastructure to be installed for IFE data transfer at this airport terminal. The objective in this simulation is to find the number of base stations required for Heathrow terminal 5B for IFE scenario.

Network Topology: After optimizing the network for IFE scenario, now the simulation is carried out using actual airport terminal map. An accurate base station placement can reduce the number of base stations, adequate signal coverage of desired area, spectral efficiency and lower installation costs. Base station placement has strong influence on network throughput, channel assignment, and efficient spectrum utilization in Wi-Fi network [8]. Figure 10 shows the Heathrow airport terminal 5 and Charles de Gaulle terminal 1. Heathrow terminal 5B is selected for network simulation. The length of this terminal is about $680 \mathrm{~m}$ and on each side of this terminal, total 10 aircraft can be parked. The aircraft are parked within the coverage distance of $150 \mathrm{~m}$ from terminal building. Using the same link distance measurements, a network topology has been developed for Heathrow terminal 5B as shown in Figure 11 with one, three and five base stations respectively.

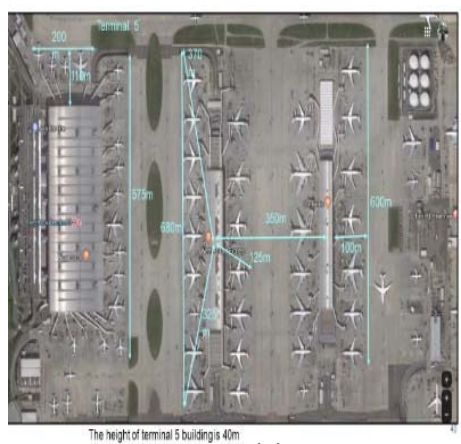

(a)

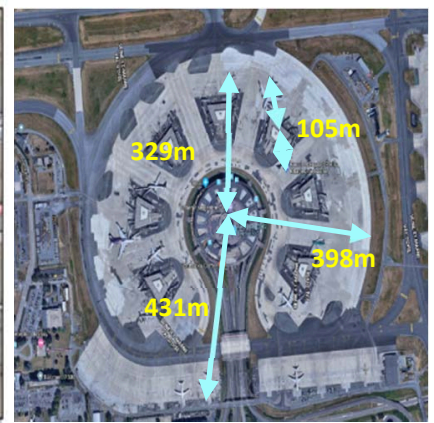

(b)
Figure 10: Airport layouts - (a) Heathrow terminal 5B, (b) Charles de Gaulle terminal 1Inflight entertainment scenario

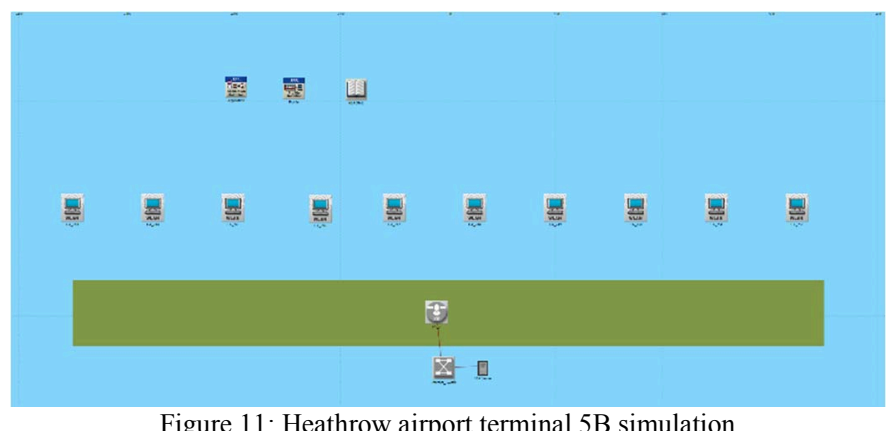

Figure 11: Heathrow airport terminal 5B simulation

Result Analysis: Throughput results in Figure 12 shows that with an increase in number of base stations, the throughput per users is also increased from 74.77 to 233 when number of base stations are changing from 1 to 5 . For IFE scenario, we are interested in high throughput/user. So, it is recommended to use at least three or more access points to accommodate all 10 aircraft at terminal $5 \mathrm{~B}$ gates for simultaneous IFE data transmission at higher speeds.

\section{F. Simulation SC-6.2 Charles de Gaulle Airport Terminal-1}

Objective: The objective of this simulation is to find the number of base stations required for Charles de Gaulle terminal 1 for IFE scenario.

Network Topology: This simulation is carried out for Terminal 1 of Charles de Gaulle airport. The structure of this terminal is ring shape different from Heathrow terminal 5B. It contains 7 buildings distributed in circle and each building can accommodate maximum three aircraft at a time. The aircraft are parked within a radius of approximately $350 \mathrm{~m}$ from the centre of the terminal. The link distance between each of seven buildings and aircrafts is within $150 \mathrm{~m}$ range.

Results Analysis: Figure 13 shows the impact of increasing the number of base stations to accommodate the communication coverage to all aircraft at the terminal 1 of Charles de Gaulle airport. The number of base stations are increased from 4 to 8 , it has been observed that average throughput per user is increased from $56.1 \mathrm{Mbps}$ to $98.4 \mathrm{Mbps}$.

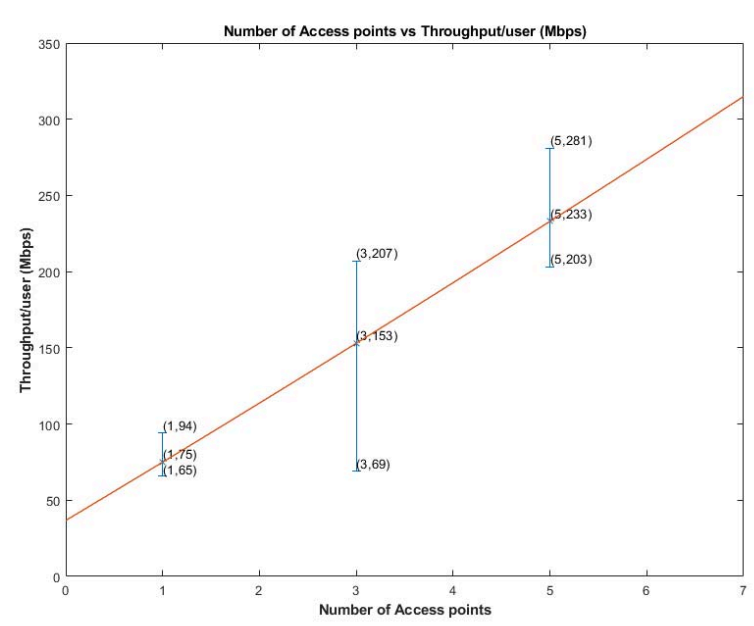

Figure 12: Number of access points vs throughput/user (Mbps) 


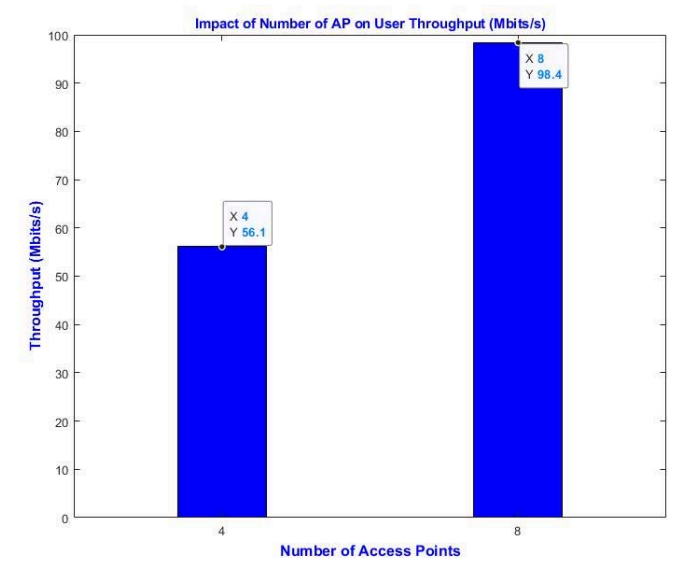

Figure 13: Impact of number of access point on user throughput

\section{CONCLUSION}

This paper serves as a roadmap to provide general rules and guidelines on suitability of wireless datalinks for IFE updates at the airports, study QoS requirements and perform optimization. It is dealing with several aspects of the datalink deployment, such as airport operational areas, airport layouts, radio frequency, interference with other systems etc. before conducting a capacity and coverage analysis. Particular uses cases for high-capacity Wi-Fi deployment in Charles de Gaulle and Heathrow international airports were investigated.

The robust and reliable deployment of wireless systems is complicated at airport because of its size and architecture. One of the challenges is the need to cover a large area outdoors, while considering the cost of infrastructure to be installed carefully. A unique situation for airports is the presence of the large metal bodies of aircraft, which can pose a challenge for radio transmission and reception.

Wireless communication systems face another problem, as different airlines and other air transport industry players use an airport's network on a regular basis, a global standard wireless service is necessary to regulate the traffic on the airport surface without failure of the system. With this system, an airline and aircraft can use the wireless connectivity at any airport without any configuration changes.

Wi-Fi is the most promising technology for IFE scenario because of different standard versions available for high speed data transmission, which is the requirement of IFE scenario as there is only $45-50$ minutes turnaround time available to download IFE updates during flight operations.

The simulation carried out for communication range determination for Wi-Fi standards identified that both $802.11 \mathrm{n}$ and 802.11ac standards meet the minimum distance requirement of $150 \mathrm{~m}$ with appropriate transmission power level. However, since $802.11 \mathrm{ac}(3.4 \mathrm{Gbps})$ is capable of providing high data speed compared to 802.11 n (600Mbps), so $802.11 \mathrm{ac}$ is recommended for IFE scenario simulation in this work. However, data link connectivity range can be increased beyond $150 \mathrm{~m}$ by increasing transmission power level of the base station or using narrow beam directional antennas with appropriate gain to achieve the desired range. By adopting above measures, the Wi-Fi coverage can be extended to provide connectivity to the aircraft parked at the apron or remote areas at the airport, however, at the expense of reduction in data rates. By adopting optimized configuration, a significant improvement has been observed in user throughput. It has been observed that a maximum of $\sim 276 \mathrm{Mbps}$ data rate is obtained when a single user is downloading a file size of $1 \mathrm{~GB}$ from a server. However, this data rate is further increased when file size to be transferred is increased. It has been concluded with an increase of file size, channel utilization and user throughput are growing as well. It was found from simulation results that a maximum of 993Mbps throughput is achieved when transferring a daily IFE updates equivalent to 20GB using a single user connected with base station at a distance of $100 \mathrm{~m}$ from base station.

The impact of increasing number of users associated with certain base station has been simulated. As the number of users contending to access the same channel is increased, delays are increased in the network due to more packet drops when network channel is not available for transmission, which results in reduction in individual user throughput. The number of users were varied from 1-10. The user throughput was decreased from $276 \mathrm{Mbps}$ to $87 \mathrm{Mbps}$ as the number of users increased from 1 to 10 while downloading $1 \mathrm{~GB}$ file from server. In airport environment, when more number of aircraft arrive at the terminal gate, these associate with base station to initiate IFE data updates, which can increase channel access rate resulting in an improvement in channel utilization at one side, however, it can also create network congestion in case of simultaneous requests for transmission from multiple users. So, there is a trade-off between the number of users associated with each base station and throughput so that IFE data can be updated within turnaround time of 45 minutes. An accurate base station placement can reduce the number of base stations, adequate signal coverage of desired area, spectral efficiency and lower installation costs. Base station placement has strong influence on network throughput, channel assignment, and efficient spectrum utilization in Wi-Fi network. To obtain the information of actual number of aircraft association with base stations at airport terminal, a simulation was carried out using layouts of two airport terminals: Heathrow airport terminal 5B, and Charles de Gaulle airport terminal 1. The network topologies for both of these terminals are chosen according to their layouts. For example, for Charles de Gualle terminal, the aircraft are parked in a circle around the terminal buildings, so, an omni-directional transmission is recommended for this layout.

Most of Wi-Fi devices use omnidirectional antennas, which emit the signals to all sides from the antennas and may cause considerable signal influence to other nearby wireless devices. Directional antenna is a good choice to avoid the surrounding wireless interference. The directional transmission can make the scan process difficult, since the transmission path may not pass through the interfering network coverage, thus can avoid or reduce the interference level. A single Wi-Fi base station with multiple directional antennas can have multiple transmissions at the same time. This transmission arrangement 
is useful in reusing the same frequency channels, hence, increasing the spectrum efficiency.

For Heathrow airport terminal 5B, where aircraft are parked in a lane with at least $50 \mathrm{~m}$ distance among them, the directional antenna transmission is recommended and it has been found that a 60-degree directional antenna beam width provides a coverage up to three aircraft parked within $100 \mathrm{~m}$ distance. Simulation has been carried out to get an estimate of infrastructure (base stations) cost required for each layout. It has been observed that with an increase in number of base stations, user throughput is also increased, for Heathrow terminal with 5 base stations each serving 2 aircraft at a time, the maximum and minimum user throughput obtained are 281 and 203Mbps respectively, whereas at Charles de Gaulle airport, if each base station is serving three users then a user throughput of around $100 \mathrm{Mbps}$ is achieved with a transmission power level of $250 \mathrm{~mW}$ and at a distance of $100 \mathrm{~m}$ from base station. Based on above simulation results, it is recommended that for IFE scenario, a single base station should serve no more than two aircraft at the same time to avoid delays and achieve the user throughput of more than 200Mbps.

The upcoming 5G technology which is promising high data rates in Gbps is one of the strong candidates for future airport connectivity. Other potential candidates for IFE scenario include millimetre wave technology and visible light communications where a data rate of $10 \mathrm{Gbps}$ is expected. These two potential technologies are still under research phase and their products are not available off-the-shelves at present. Also, for these technologies, the data is transmitted in narrow beam width providing a high gain so point to point connectivity is required which can be a challenging in gate terminal environment as base station transmitting antenna needs to be in line of sight with aircraft receiving antenna.

\section{ACKNOWLEDGMENT}

This project is carried out with the collaboration of Cranfield University, UK and Thales, UK. The authors of this publication are thankful to Thales, UK for providing funding for this study project.

\section{REFERENCES}

[1] D. Gray, "AeroMACS - Delivering Next Generation Communications to the Airport Surface," 2015.

[2] J. N. Tavares, "Data communications between an airplane Airbus a 350 and the ground infrastructure," University of Lisbon, 2014.

[3] I. Gheorghisor, V. Lakshminarayan, L. Globus, D. Arnstein, and F. Box, "Analyses and simulations for Aeronautical Mobile Airport Communications System," ICNS 2016 Secur. an Integr. CNS Syst. to Meet Futur. Challenges, pp. 2C2-1-2C2-13, 2016.

[4] N. W. Paper, "Airport private wireless solutions," 2019.

[5] ARINC, "Datalink Ground Systems Standarad And Interface Specification - ARINC Specification 620-9," 2017.

[6] A. A. Khan, K. Been, and B. Biplob, "A Study on Delay, Throughput and Traffic Measurement for Wi-Fi Connected Stations Based on MAC Sublayer," IEEE Commun. Surv. Tutorials, vol. 20, no. 1, pp. 197-216, 2019.

[7] F. J. Martinez, C. K. Toh, J. Cano, C. T. Calafate, and P. Manzoni, "A survey and comparative study of simulators for vehicular ad hoc networks ( VANETs )," 2009.

[8] W. Jiang, "OPNET-based WLAN modeling and its performance testing," Chem. Eng. Trans., vol. 51, pp. 361-366, 2016.

[9] Z. T.Alisa, "Evaluating the Performance of Wireless Network using OPNET Modeler," Int. J. Comput. Appl., vol. 62, no. 13, pp. 22-28, 2013.

[10] D. B. Rawat, D. C. Popescu, and M. Song, "Performance enhancement of EDCA access mechanism of IEEE 802.11e wireless LAN," 2008 IEEE Radio Wirel. Symp. RWS, pp. 507-510, 2008.

[11] A. M. Ghaleb, D. Chieng, A. Ting, K. H. Kwong, K. C. Lim, and H. S. Lim, "Throughput analysis of IEEE802.11n using OPNET," IET Conf. Publ., vol. 2012, no. 614 CP, 2012.

\section{AUTHORS AND AFFILIATIONS}

Dr. Shahid Ayub has been working as a Research Fellow at center of Autonomous and Cyberphysical systems, Cranfield University, UK. He has received his $\mathrm{PhD}$ in Communication Systems from Lanacster University, UK in 2014. His areas of interests are datalink communications systems, autonomous vehicles and human machine interface, Wireless networking of drones, Wireless industrial automation systems, Security and privacy, and Internet of things.

Dr. Ivan Petrunin received his MSc degree in Design and Manufacturing of Electronic Equipment from National Technical University of Ukraine in 1998, $\mathrm{PhD}$ degree in Signal Processing for Condition Monitoring from Cranfield University, UK, in 2013.

His current research focus is in areas of applied signal processing for autonomous systems with particular emphasis on communication, navigation and surveillance aspects, such as cognitive communication schemes, assured multi-sensor navigation and remote sensing.

Prof. Antonios Tsourdos received the M.Eng. degree in electronic, control and systems engineering from the University of Sheffield, Sheffield, U.K., in 1995, the M.Sc. degree in systems engineering from Cardiff University, Cardiff, U.K., in 1996, and the Ph.D. degree in nonlinear robust missile autopilot design and analysis from Cranfield University, Cranfield, U.K. in 1999. He is currently a Professor of control systems with Cranfield University, where he was the Appointed Head of the Autonomous Systems Group in 2007. He has published over 100 peer-reviewed journal and conference papers.

Prof. Tsourdos was a member of the Team Stellar, the winning team for the U.K. MoD Grand Challenge in 2008 and the IET Innovation Award (Category Team, 2009). He is an editorial board member on several international publications, including IMechE and IEEE. He is a member of the IFAC Technical Committee on Intelligent Autonomous Vehicles, the IET Executive Team on Robotics and Automation, and the ATI Autonomous Systems National Technical Committee. He was also involved in the SEAS DTC on Autonomous Systems Verifications. He has also been engaged in research on guidance and control for single and multiple vehicles as well as verifiable autonomy of autonomous systems and lately dealing with the newly important subjects of integrated system health management and cyber-physical systems.

Saba Al-Rubaye received her Ph.D. degree in electrical and electronic engineering from Brunel University London. She is currently a Senior Lecturer in the School of Aerospace, Transport and Manufacturing at Cranfield University, UK. She is an active research group member of IEEE P1932.1 Standard of License/unlicensed Interoperability and IEEE P1920.2 Standard for Vehicle-to-Vehicle Communications for Unmanned Aircraft Systems. Her research interests are in the areas of Wireless communications, UAV networking, and Autonomous systems. Dr. Al-Rubaye is recognized as a Chartered Engineer- CEng and Senior Member of IEEE. 
$2020-11-18$

\title{
In-flight entertainment datalink analysis and simulation
}

\author{
Ayub, Shahid
}

IEEE

Ayub S, Petrunin I, Tsourdos A, et al., (2020) In-flight entertainment datalink analysis and simulation. In: 2020 AIAA/IEEE 39th Digital Avionics Systems Conference (DASC), 11-15 October 2020.San Antonio, TX, USA

https://doi.org/10.1109/DASC50938.2020.9256432

Downloaded from Cranfield Library Services E-Repository 